\title{
Energy and exergy evaluation of an integrated solar heat pipe wall system for space heating
}

\author{
ROONAK DAGHIGH* and ABDELLAH SHAFIEIAN \\ Department of Mechanical Engineering, University of Kurdistan, Kurdistan, Iran \\ e-mail: r.daghigh@uok.ac.ir; daghighm@gmail.com
}

MS received 8 May 2015; revised 15 October 2015; accepted 16 February 2016

\begin{abstract}
In this paper, an integrated solar heat pipe wall space heating system, employing double glazed heat pipe evacuated tube solar collector and forced convective heat transfer condenser, is introduced. Thermal performance of the heat pipe solar collector is studied and a numerical model is developed to investigate the thermal efficiency of the system, the inlet and outlet air temperatures and heat pipe temperature. Furthermore, the system performance is evaluated based on exergy efficiency. In order to verify the precision of the developed model, the numerical results are compared with experimental data. Parametric sensitivity for design features and material associated with the heat pipe, collector cover and insulation is evaluated to provide a combination with higher thermal performance. Simulation results show that applying a solar collector with more than 30 heat pipes is not efficient. The rate of increasing in temperature of air becomes negligible after 30 heat pipes and the trend of the thermal efficiency is descending with increasing heat pipes. The results also indicate that at a cold winter day of January, the proposed system with a 20 heat pipe collector shows maximum energy and exergy efficiency of $56.8 \%$ and $7.2 \%$, which can afford warm air up to $30^{\circ} \mathrm{C}$. At the end, the capability of the proposed system to meet the heating demand of a building is investigated. It is concluded that the best method to reach a higher thermal covered area is to apply parallel collectors.
\end{abstract}

Keywords. Energy efficiency; exergy; solar wall; evacuated heat pipe collector; space heating; Sanandaj.

\section{Introduction}

Heat recovery devices, like heat pipes, are intended to compensate a part of energy, consumed in HVAC systems. The working fluid inside a heat pipe is vaporized inside the evaporator section and moves toward the condenser. In this section the latent heat energy is transferred to the cooling fluid. The condensate fluid then returns to the heating section through the capillary structure $[1,2]$.

Solar thermal has been studied widely and is considered as an efficient and economical solution, among renewable technologies, to overcome energy demands. The idea of passive solar space heating by heat pipes was initially studied by Corliss. He analyzed the passive solar heating for a variety of weathers. The heat pipe system performed better in all weathers [3]. Rice reviewed the application of heat pipe in passive solar heating systems. Experimental performance and simulated data determined that these systems worth additional research [4]. Albanese et al [5] studied a passive heat pipe solar space heating system mounted on wall. Their results showed the better performance of heat pipe system, especially in cold climatic conditions. Robinson et al designed a prototype of heat pipe

*For correspondence passive solar heating system. The prototype system was tested in climatic condition of Louisville, KY. Their system reached the average daily efficiency of $61.4 \%$ [6]. Du et al designed an experimental platform to investigate the thermal performance of heat pipe solar collectors. The effect of parameters like absorber area and incidence angle on the inlet and outlet temperatures and overall efficiency was studied [7].

Varga et al employed heat pipes to transfer heat in the cooling season of southern European climate [8]. Chan et al reviewed passive solar heating and cooling systems based on the working mechanisms [9].

It has been proven that an exergy study (or second law study) is a useful tool in analysis of energy systems [10,11]. Akpinar and Koçyigit designed and experimentally studied the performance of a flat-plate collector used for air heating. The collector contains obstacles on the absorber plates. The results were compared with a collector without attached obstacles based on energy and exergy analyses [12]. Bouadila et al also designed a solar collector with phase change materials attached to the surface as latent storage energy, and investigated energy and exergy efficiency [13]. It has been proven that the highest exergy destruction (irreversibility) in solar systems occurs in the solar collector. The daily energy and exergy efficiency of solar collector varies between $25 \%$ 
$65 \%$ and $1 \%-3.5 \%$ respectively [14]. Energy and exergy performance evaluation of solar air heaters with inserted porous baffles was conducted [15]. The obtained results showed that the highest temperature difference is achieved in air mass flow rate of $0.025 \mathrm{~kg} / \mathrm{s}$. So, it is evident that the exergic analyses of solar systems are very few in comparison with energic analyses.

In this paper, the authors will introduce an integrated solar heat pipe wall system for space heating employing double glazed heat pipe evacuated tube solar collector and forced convective heat transfer condenser and will evaluate energy and exergy performance of the proposed system. Finally, the capability of the proposed system to meet the heating demand of a building will be investigated.

\section{System description}

Figure 1 shows the proposed system schematically. If the outlet air temperature from collector goes beyond the thermal load, extra energy will be stored in a latent heat storage for future use. The system comprises the outdoor and indoor (between two sides of the wall) parts. The outdoor part is a double glazed heat pipe evacuated tube solar collector. Received solar irradiation is used to vaporize heat pipe working fluid. The air which is circulated by fans absorbs heat at the condenser section, which results in both condensation of the vapor and increase in air temperature. So, the heat from the heat pipe condenser is transferred to the circulating air, which is mixed with fresh air for better ventilation, through the copper manifold, that plays the role of heat exchanger. The outdoor part is shown in figure 2. It has been proved that the double-glazed evacuated collectors result in a better performance in comparison with single glazing ones [16].

\section{Mathematical analysis of the thermal processes}

Matlab codes were created to simulate the performance of the solar system and the results were compared based on the system efficiency and exergy analysis. Balance equations of energy and exergy in steady state, constant-flow process is used, and appropriate energy and exergy equations are derived for the components of system.

\subsection{Collector}

The thermal energy balance of solar collector can be expressed as [16]:

$$
Q_{\mathrm{ab}}(t)=Q_{\mathrm{en}}(t)-Q_{\text {loss }}(t)
$$

$Q_{\text {en(t) }}$, solar radiation that passes the glass cover and absorbs by the evaporator surfaces, can be calculated using Eq. (2) [17].

$$
Q_{\mathrm{en}}(t)=\tau_{\mathrm{go}} \tau_{\mathrm{gi}} \alpha_{\mathrm{c}} A_{\mathrm{ab}} N_{\mathrm{hp}} I(t) .
$$

$Q_{\text {loss(t) }}$ which is the lost energy from the absorbers to the ambient, due to temperature difference, can be calculated by [18]:

$$
\begin{gathered}
Q_{\text {loss }}=\frac{T_{\mathrm{ab}}-T_{\mathrm{amb}}}{R_{\mathrm{ab}-\mathrm{gi}}+R_{\mathrm{gi}}+R_{\mathrm{gi}-\mathrm{go}}+R_{\mathrm{go}}+R_{\mathrm{go}-\mathrm{amb}}} \\
R_{\mathrm{ab}-\mathrm{gi}}=\frac{1}{h_{\mathrm{air}}\left(\frac{A_{\mathrm{ab}} N_{\mathrm{hp}}+A_{\mathrm{gi}}}{2}\right)}+\frac{\frac{1-\varepsilon_{\mathrm{ab}}}{\varepsilon_{\mathrm{ab}} A_{\mathrm{ab}} N_{\mathrm{hp}}}+\frac{1}{A_{\mathrm{ab}} N_{\mathrm{hp}} F_{\mathrm{ab}-\mathrm{g}}}+\frac{1-\varepsilon_{\mathrm{gi}}}{\varepsilon_{\mathrm{gg} i} A_{\mathrm{gi}}}}{\left.R_{\mathrm{ab}}+T_{\mathrm{gi}}\right)\left(T_{\mathrm{ab}}^{2}+T_{\mathrm{gi}}^{2}\right)}=\frac{t_{\mathrm{gi}}}{k_{\mathrm{gi}} A_{\mathrm{gi}}} \\
R_{\mathrm{go}-\mathrm{amb}}=\frac{1}{A_{\mathrm{g}}}\left(\frac{1}{h_{\mathrm{amb}}}+\frac{1}{\sigma \varepsilon_{\mathrm{go}}\left(T_{\mathrm{go}}+T_{\mathrm{amb}}\right)\left(T_{\mathrm{go}}^{2}+T_{\mathrm{amb}}^{2}\right)}\right) \\
R_{\mathrm{gi}-\mathrm{go}}=\frac{\frac{1-\varepsilon_{\mathrm{gi}}}{\varepsilon_{\mathrm{gi}} A_{\mathrm{gi}} N_{\mathrm{hp}}}+\frac{1}{\sigma\left(T_{\mathrm{gi}}+T_{\mathrm{go}}\right)\left(T_{\mathrm{gi}}^{2}+T_{\mathrm{go}}^{2}\right)} .}{k_{\mathrm{go}} A_{\mathrm{go}}}
\end{gathered}
$$

Since all radiation leaving the absorber and inner glass reach the inner and outer glass respectively, $F_{\text {ab-g }}$ and $F_{\text {gi-go }}$ are equal to one [19].

\subsection{Heat pipes}

Heat transfer of the heat pipe can be modeled by a number of thermal resistances that includes evaporator and condenser wall resistances, wick conduction resistances and internal resistance [1].

$$
\sum R=R_{\mathrm{e}, \mathrm{p}}+R_{\mathrm{e}, \text { wick }}+R_{\mathrm{e}, \mathrm{i}}+R_{\mathrm{v}}+R_{\mathrm{ci}}+R_{\mathrm{c}, \mathrm{p}} .
$$

3.2a Heat pipe evaporator resistances: Evaporator wall, wick conduction and internal resistances at the evaporator can be expressed as follows [20]:

$$
\begin{gathered}
R_{\mathrm{e}, \mathrm{p}}=\frac{\ln \left(d_{\mathrm{o}} / d_{\mathrm{i}}\right)}{2 \pi k_{\mathrm{p}} L_{\mathrm{e}}} \\
R_{\mathrm{e}, \text { wick }}=\frac{\ln \left(d_{\mathrm{o}, \text { wick }} / d_{\mathrm{i}, \text { wick }}\right)}{2 \pi k_{\text {wick }} L_{\mathrm{e}}} .
\end{gathered}
$$

The effective thermal conductivity of screen mesh is calculated from the following equation:

$$
k_{\text {wick }}=\frac{k_{1}\left[k_{1}+k_{\mathrm{s}}-\left(1-\varepsilon_{\text {wick }}\right)\left(k_{1}-k_{\mathrm{s}}\right)\right]}{k_{1}+k_{\mathrm{s}}+\left(1-\varepsilon_{\text {wick }}\right)\left(k_{1}-k_{\mathrm{s}}\right)}
$$

The internal thermal resistance, $\mathrm{R}_{\mathrm{e}, \mathrm{i}}$, can be written as [20]: 


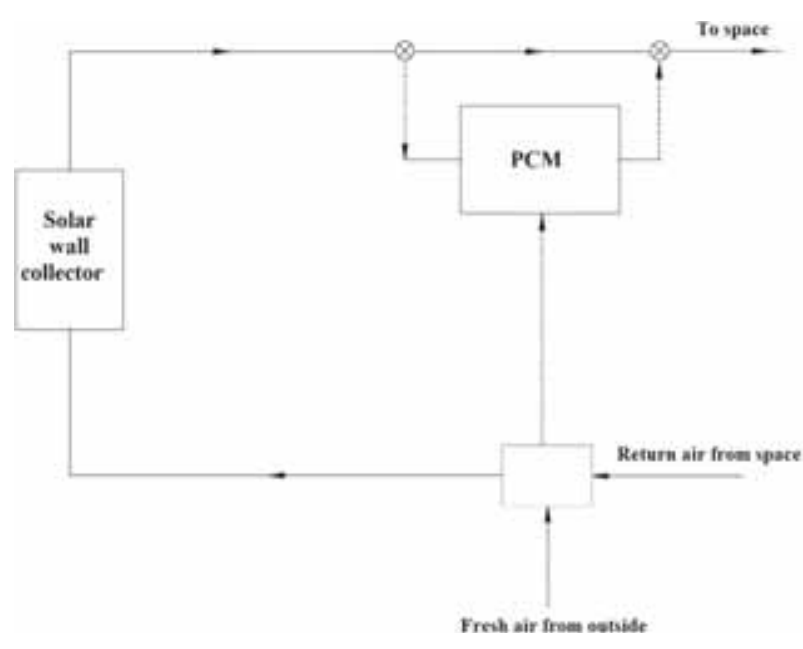

Figure 1. Schematic of the air heating system.

$$
R_{\mathrm{e}, \mathrm{i}}=\frac{2}{h_{\mathrm{e}} \pi d_{\mathrm{i}} L_{\mathrm{e}}} .
$$

The film coefficient is expressed as [21]:

$$
h_{\mathrm{e}}=\frac{k_{\mathrm{l}}}{t_{\text {wick }}} .
$$

3.2b Heat pipe condenser resistances: The resistance related to the conduction from the inner wall to the external surface is [20]:

$$
R_{\mathrm{c}, \mathrm{p}}=\frac{\ln \left(d_{\mathrm{o}} / d_{\mathrm{i}}\right)}{2 \pi k_{\mathrm{p}} L_{\mathrm{c}}} .
$$

The thermal resistance of the condensing process is

$$
R_{\mathrm{c}, \mathrm{i}}=\frac{1}{h_{\mathrm{c}, \mathrm{i}} \pi d_{\mathrm{i}} L_{\mathrm{c}}} .
$$

The heat transfer coefficient condensing process can be achieved by [20]:

$$
h_{\mathrm{c}, \mathrm{i}}=0.728\left[\frac{g \rho_{1}\left(\rho_{1}-\rho_{\mathrm{v}}\right) k^{3} \lambda}{d_{\mathrm{i}} \mu_{\mathrm{i}} \Delta T_{\mathrm{i}}}\right]^{1 / 4} .
$$

3.2c Thermal analysis of heat pipe array: The outlet air temperature of the first condenser is taken as the inlet air temperature of the second one inside the manifold, and so on. As stated in more scientific contexts, preferred indoor temperature has an average of $23^{\circ} \mathrm{C}$. Suitable temperature for old people (aged 58 and above) is about $23^{\circ} \mathrm{C}$ too [22]. Therefore, the room temperature is assumed to remain at constant value of $23^{\circ} \mathrm{C}$. There is no ideal value for fresh air that should be added, because it depends on different factors, like number of occupants, air flow rate, etc., but a proper estimation of fresh air is about 30\% [23]. The phase change occurs inside the condenser section of heat exchanger. Working fluid vapor condenses almost at a constant temperature. Therefore, the effectiveness-NTU method is used to analyze the thermal performance of heat pipe array.

\subsection{Exergy efficiency}

The analysis assumptions in this study are [12]:

- Equations are developed under steady state and steady flow.

- Potential and kinetic energy effects are neglected and there is no chemical or nuclear reactions.

- Air is considered as an ideal gas, so has a constant specific heat.

- The directions of heat transfer to the system is considered positive.

Exergy balance equation is applied to achieve exergy efficiency [14]:

$$
\sum \dot{E} x_{\text {in }}-\sum \dot{E} x_{\text {out }}=\sum \dot{E} x_{\text {dest }}
$$

or

$$
\dot{E} x_{\text {heat }}-\dot{E} x_{\text {work }}+\dot{E} x_{\text {mass,in }}-\dot{E} x_{\text {mass,out }}=\dot{E} x_{\text {dest }} .
$$

It can also be written as

$\sum\left(1-\frac{T_{0}}{T_{\mathrm{k}}}\right) \dot{Q}_{\mathrm{k}}-\dot{W}+\sum \dot{m}_{\mathrm{in}} \psi_{\text {in }}-\sum \dot{m}_{\text {out }} \psi_{\text {out }}=\dot{E} x_{\text {dest }}$.

$\psi$ is flow exergy and can be calculated by

$$
\psi=\left(h-h_{0}\right)-T_{0}\left(s-s_{0}\right) .
$$

Exergy efficiency can be defined as the ratio of useful delivered exergy to the absorbed exergy by the solar collector [24]:

$$
\eta_{\mathrm{sc}}=\frac{\dot{E} x_{\mathrm{u}}}{\dot{E} x_{\mathrm{sc}}}
$$

with

$$
\dot{E} x_{\mathrm{u}}=\dot{m}_{\mathrm{w}}\left[\left(h_{\mathrm{o}}-h_{\mathrm{i}}\right)-T_{0}\left(s_{\mathrm{o}}-s_{\mathrm{i}}\right)\right]
$$

or

$$
\dot{E} x_{\mathrm{u}}=\dot{m} C_{\mathrm{w}}\left[\left(T_{\mathrm{o}}-T_{\mathrm{i}}\right)-T_{0}\left(\ln \frac{T_{\mathrm{o}}}{T_{\mathrm{i}}}\right)\right]
$$

and

$$
\dot{E} x_{\mathrm{sc}}=A I_{\mathrm{T}}\left[1+\frac{1}{3}\left(\frac{T_{0}}{T_{\mathrm{sr}}}\right)^{4}-\frac{4}{3}\left(\frac{T_{0}}{T_{\mathrm{sr}}}\right)\right] .
$$

While using mentioned equation in calculating the exergy of solar radiation, solar radiation temperature, $T_{\mathrm{sr}}$, is taken to be $6000 \mathrm{k}$ [25]. 

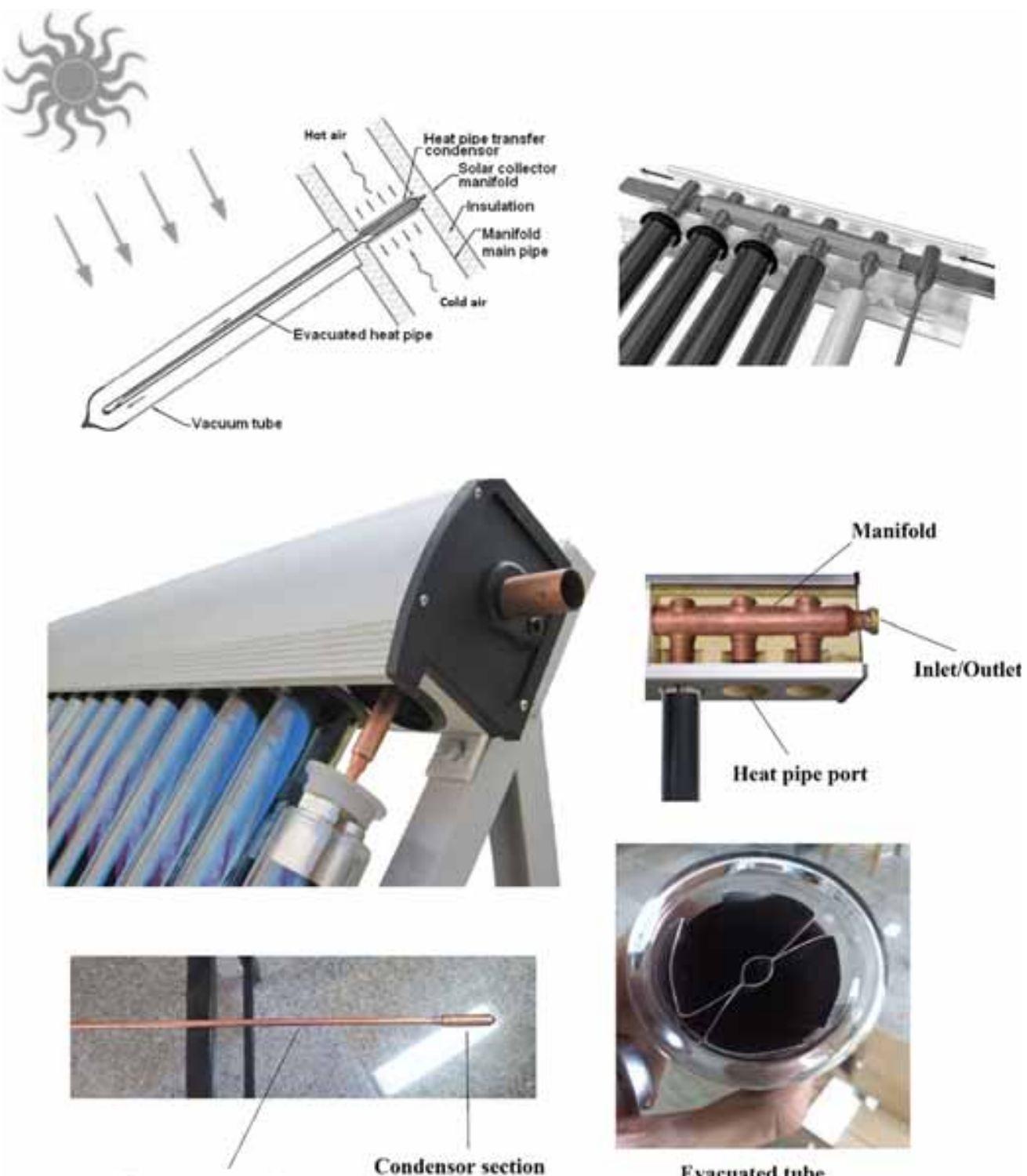

Evaporator section

Condensor section

Figure 2. Evacuated tube heat pipe solar collector.

\subsection{Heating load}

In order to reach a desirable level of comfort for occupants, the estimation of energy, which should be added to the building, is necessary. The heating load of a building in winter consists of two main parts, which are heat losses through building envelope components such as walls and ceiling, and cold air penetration inside building. So, an usual space, with one wooden door at the eastern wall and one double glazed window with air space of $1.2 \mathrm{~cm}$ at the western wall, is considered. The area of door and window are $2 \mathrm{~m}^{2}$ and $1.5 \mathrm{~m}^{2}$, respectively. According to statistical data of Sanandaj, the outside and inside design temperatures are $23.3^{\circ} \mathrm{C}$ and $-12.7^{\circ} \mathrm{C}$ respectively. Loss coefficients are calculated due to the construction materials of walls and ceiling. Walls are made of hollow clay tile, face brick and gypsum board and ceiling is made of concrete, $2.54 \mathrm{~cm}$ thick insulation and interior gypsum board. In accordance with the mentioned design and materials, the heat loss coefficients of walls, ceiling, door and window are 1.653, $0.741,2.565$ and $3.7 \mathrm{~W} / \mathrm{m}^{2}{ }^{\circ} \mathrm{C}$, respectively [23].

The analysis assumptions in this study are:

- There is one-dimensional parallel heat flow.

- Heat sources inside building, like occupants, are neglected.

- The construction materials are thermally homogeneous.

- There is no thermal storage and heat transfer is instantaneous. 
Envelope heat losses:

Envelope heat losses consist of all conductive heat transfers through walls, ceiling, doors and windows, and can be calculated by [23]:

$$
q=U A\left(T_{\mathrm{di}}-T_{\mathrm{do}}\right)
$$

where $U$ is the overall heat transfer coefficient, $T_{\mathrm{di}}$ and $T_{\mathrm{do}}$ are inlet and outlet design temperatures.

Air penetration heat loss:

The first step in estimating the air penetration heat loss is to calculate the volume rate of the penetrating air as followed [23]:

$$
V=n \times v
$$

where $v$ is the volume of space and $n$ is the number at which the whole air of space is replaced per hour. This parameter is equal to 1.5 for buildings with one door and one window facing out.

Air penetration heat loss is calculated by

$$
q=1200 \times V \times\left(T_{\mathrm{do}}-T_{\mathrm{di}}\right) .
$$

Since the situation is not the same for all the walls, orientation factors are considered in calculations and the insurance factor is taken to be $10 \%$ [23].

\subsection{Error analysis}

In order to compare two sets of measurements, the standard error in the difference is used. The standard error in the difference is as follows [26]:

$$
S_{\left(\bar{x}_{\mathrm{A}}-\bar{x}_{\mathrm{B}}\right)}=\sqrt{\frac{S_{\mathrm{A}}^{2}}{N_{\mathrm{A}}}+\frac{S_{\mathrm{B}}^{2}}{N_{\mathrm{B}}}}
$$

where $S_{\mathrm{A}}^{2}$ and $S_{\mathrm{B}}^{2}$ are the sample variances that are calculated by

$$
s^{2}=\frac{\sum_{i=1}^{n}\left(x_{\mathrm{i}}-\bar{x}\right)^{2}}{n-1}
$$

$\bar{x}$ is the sample average that is calculated as

$$
\bar{x}=\frac{\sum_{i=1}^{n} x_{\mathrm{i}}}{n}
$$

where $x_{i}$ represents the $i$ th individual data.

\section{Results and discussion}

In order to investigate the thermal performance of the proposed system, characteristics of a winter day is chosen. Figure 3 shows the average hourly variation of ambient temperature and solar irradiation for a typical day on 25 th
January for Sannandaj (latitude 35, longitude 45, altitude $1450 \mathrm{~m}$ ), Iran [27]. The maximum solar radiation is 743 $\mathrm{W} / \mathrm{m}^{2}$, and outdoor temperature varies from -6 to $4.77^{\circ} \mathrm{C}$. Air flow rate is taken to be $186 \mathrm{~m}^{3} / \mathrm{h}$. Because of the season, the period of day is short and the maximum solar radiation is between 11:00 and 13:00.

Choosing the optimum number of heat pipes for the collector has a direct effect on the efficiency and economic justification of the system. Figure 4 shows the temperature variation of the air versus number of the heat pipes for the climatic conditions of 12:00. As the number of heat pipes increases, the rate of increasing in temperature of air decreases. This rate is very small for heat pipe 30 and upper. It can also be seen that the trend of the thermal efficiency is descending. The temperature of the air increases after each heat pipe, reducing the temperature difference between the condenser surface and the moving air. This will consequently reduce the amount of energy removed by the moving air and decreases the efficiency of the system. It can be concluded that a collector with more than 30 heat pipes is not efficient and economical.

The Specifications of proposed system are shown in tables 1 and 2 .

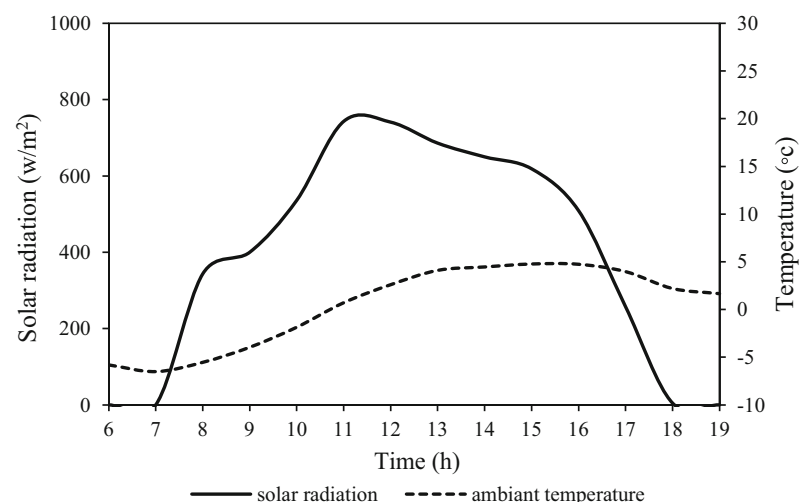

Figure 3. Average hourly radiation and ambient temperature.

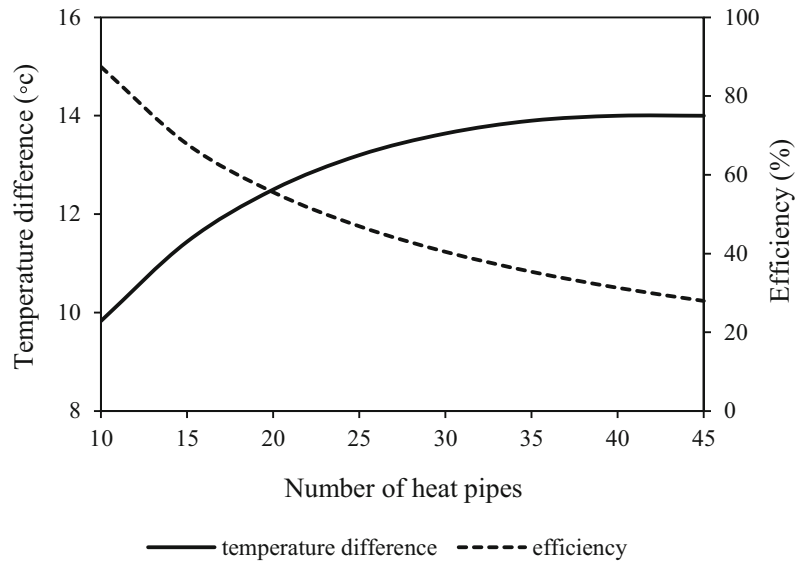

Figure 4. Increased temperature of air and efficiency vs. number of heat pipe. 
Table 1. Specification of the evacuated glass tubes.

\begin{tabular}{llcl}
\hline Transmittance & 0.88 & Outer diameter (m) & 0.058 \\
Emissivity & 0.05 & Inner diameter (m) & 0.054 \\
Thickness $(\mathrm{m})$ & 0.004 & Length $(\mathrm{m})$ & 0.8 \\
\hline
\end{tabular}

The simulation results of heat pipe temperature (Thp), absorber temperature (Tab), inlet air temperature (Ti) and outlet air temperature (To) versus time are shown in figure 5. The outlet air temperature steadily increases with time and solar irradiation. As the solar irradiation decreases, the rate of increasing in temperature of air also decreases. The energy that strikes at the heat pipe absorber plate reduces, due to decreasing of solar radiation; this lowers the heat gain of heat pipes, reducing the temperature of condenser section. Therefore, the outlet air temperature decreases. As discussed before, for better ventilation, the inlet air is a mixture of outlet and returned air from the zone, so fluctuation of ambient temperature during a day influences the outlet air temperature, makes it a function of ambient temperature too. As the ambient temperature rises; heat losses from the collector decreases, because of lower temperature difference between collector and the surrounding, which results in higher absorber temperature and higher outlet air temperature. On the other hand, higher ambient temperature means higher inlet air temperature which reduces the forced convective heat transfer coefficient, because of lower temperature difference between condenser and the inlet temperature, which reduces the outlet temperature. But, the overall effect of increasing ambient temperature is positive. Figure 6 shows the thermal efficiency versus time. Considering 11:00 and 12:00, in spite of having almost same solar radiation, because of having higher ambient temperature, the system shows better performance at 12:00. This comparison can be made for 10:00 and 16:00 too.

The temperature distribution of the outlet air versus number of the heat pipes for different solar radiations are illustrated in figure 7. As expected, the outlet air temperature increases gradually from one heat pipe to the next, while the rate of increasing in temperature decreases. The air temperature in the first condenser is about $16.77^{\circ} \mathrm{C}$, while outlet air temperature of the last heat pipe reaches about $29.34^{\circ} \mathrm{C}\left(I=741 \mathrm{~W} / \mathrm{m}^{2}\right)$.

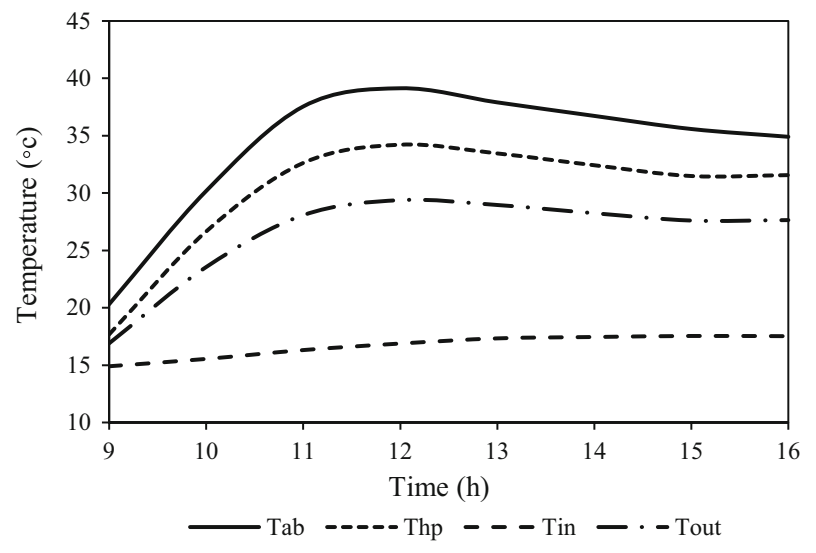

Figure 5. Temperature variation of absorber, heat pipe, inlet and outlet air temperature versus time.

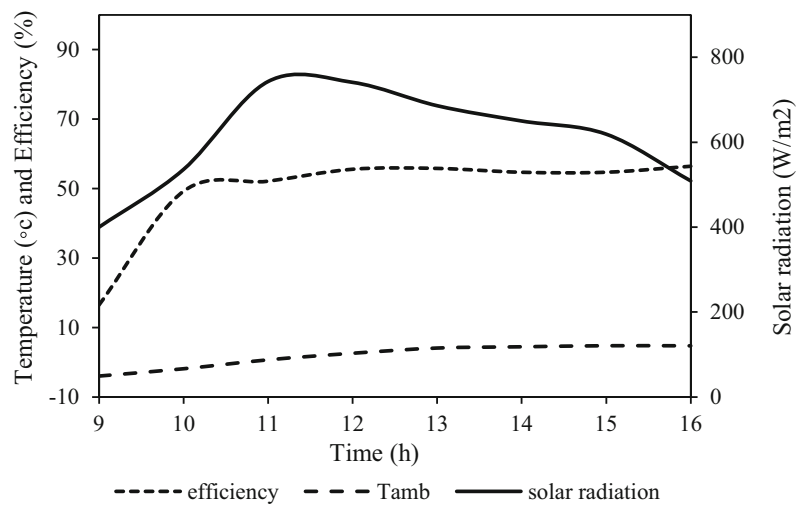

Figure 6. Efficiency versus time.

The solar efficiency (solar fraction) of the collector can be stated as the ratio of the received heat by the heat pipes divided by the total solar radiation striking on the collector. Simulation results indicated that the solar fraction is influenced by the geometry of the absorber, the thickness and the transparency of the glass cover, and the heat losses of the collector through convection, radiation, and conduction. Decreasing the conductivity of the insulating material by $37 \%$, increases the solar fraction up to $2 \%$. Among the common and investigated insulating materials, polyurethane foam shows the best performance. Increasing the transparency of the cover by $20 \%$ can increase the solar fraction up to $17 \%$. Among the investigated transparent

Table 2. Specifications of the absorbers and wicked heat pipes.

\begin{tabular}{lccc}
\hline Absorber material & Copper & Number of heat pipes & 20 \\
Absorptivity & 0.95 & Outer diameter $(\mathrm{m})$ & 0.0162 \\
Heat pipe material & Copper & Inner diameter $(\mathrm{m})$ & 0.0158 \\
Conductivity $(\mathrm{W} /(\mathrm{m} \mathrm{K}))$ & 389 & Wick structure & Two-layer screen mesh \\
Evaporator length $(\mathrm{m})$ & 0.8 & Condenser length $(\mathrm{m})$ & 0.3 \\
Working fluid & Methanol & & \\
\hline
\end{tabular}


cover materials, Iron free glass has the most solar transmittance and the most solar fraction too. Increasing the glass thickness from 1.5 to $3 \mathrm{~mm}$ decreases the solar fraction by $1.43 \%$. Switching the copper heat pipes to aluminum reduced the solar fraction by less than $1 \%$.

Exergic analyses were performed for the proposed evacuated tube heat pipe solar collector and the results are shown in figure 8 . As expected, the exergy efficiency is low for the solar collector with the maximum amount of $7.28 \%$.

In order to increase the thermal covered area of the building by the solar air heating system, the overall air flow rate and collector area should be risen. But, as discussed before, it should not exceed the maximum limit of 30 heat pipes per collector. It can be concluded that the best solution to reach a higher covered area is to apply parallel collectors, which increases the overall delivered air mass flow rate while keeps the heat pipes of collectors less than 30, simultaneously. The hourly performance of the system, with different overall collector area and constant air flow

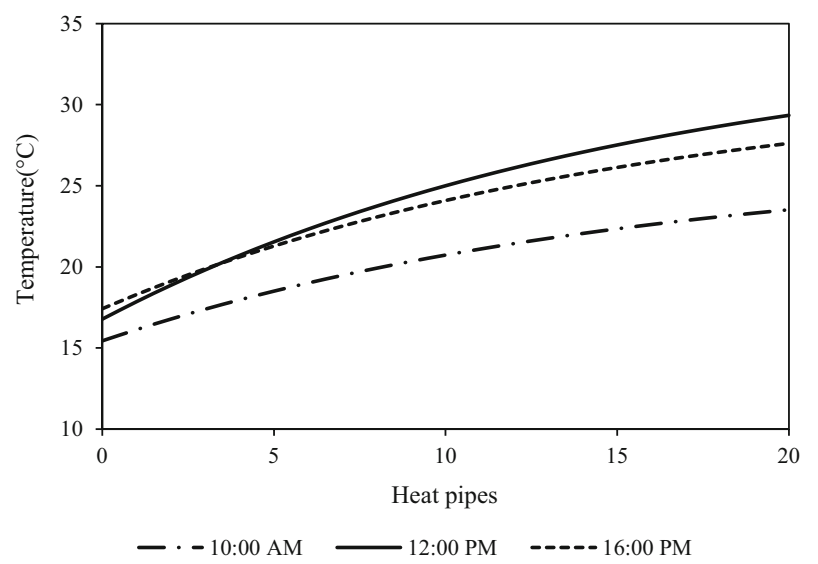

Figure 7. Temperature distribution versus number of heat pipe.

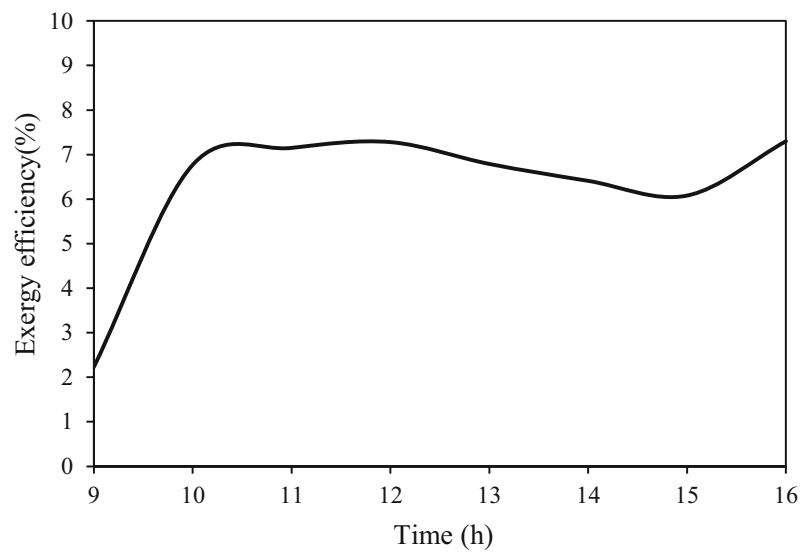

Figure 8. Exergy efficiency of solar collector versus time.

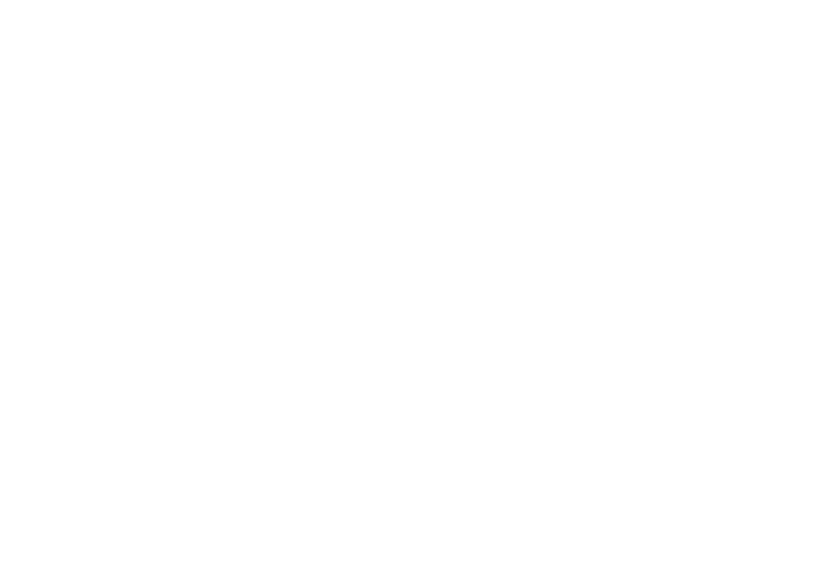

Figure 9. Hourly performance of the solar air heating system with different number of parallel collectors.

rate of $186 \mathrm{~m}^{3} / \mathrm{h}$ for each collector, is depicted in figure 9 . Each collector consists of 20 heat pipes. As expected, the maximum thermal covered area happens around 12:00, where there is the maximum solar radiation. As can be seen, increasing the overall collector area, which means increasing number of collectors in parallel, results in higher thermal covered area.

\section{Model validation}

With the aim of validating the developed model in this study, an experimental set-up was established. The intended experimental system includes (1) the heat pipe collector, (2) storage tank, (3) pump, (4) rotameter, (5) thermocouples, (6) electrical control valve, (7) the central control system (8) pipes and fittings. Figure 10 shows the heat pipe solar collector used for experimental validation. Figure 11 shows the solar intensity, ambient temperature and wind speed on the day of the experiment at August 26th in the city of Sanandaj (longitude 46, latitude 35, altitude $1450 \mathrm{~m}$ ). Solar cycle working fluid mass flow rate is $1.1 \mathrm{Lpm}$ and test hours are 9 am to $6 \mathrm{pm}$, respectively. Thermometers with precision of $0.1^{\circ} \mathrm{C}$ was used to measure the temperature of inlet and outlet water and ambient temperatures. TES1333R Solar meter was also used for solar intensity measurement. Figure 12 compares the experimental and theoretical collector output temperature. The general changes trend is similar, and the maximum relative error, between the two states, is $8.4 \%$. Error analysis result shows that the standard error is 1.91 . These two errors prove the ability of the developed mathematical model to predict the performance of heat pipe solar system. The specifications and characteristics of heat pipe solar collector is shown in table 3 . 


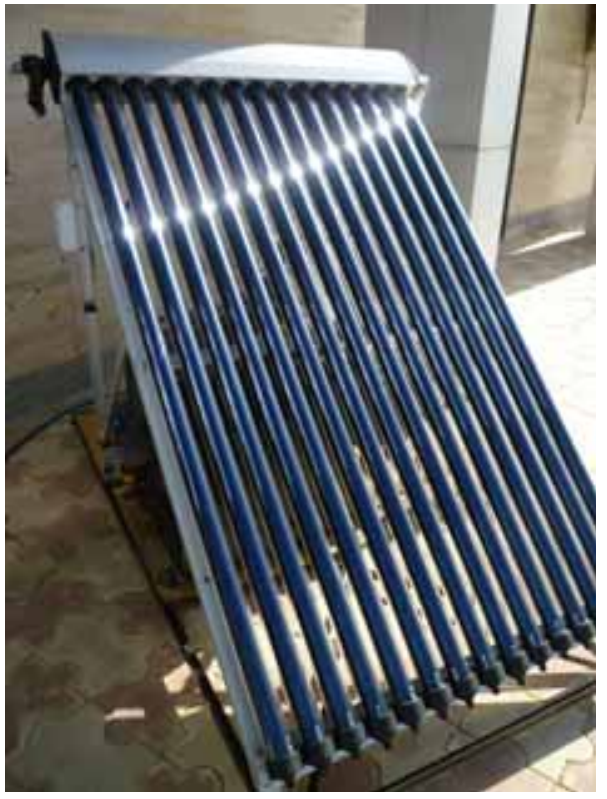

Figure 10. Heat pipe solar collector.

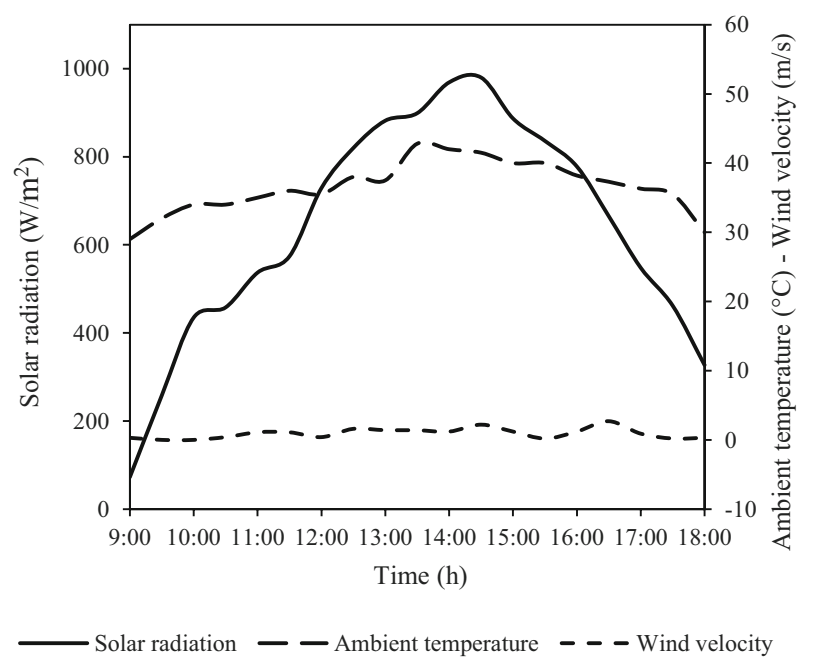

Figure 11. Solar intensity, ambient temperature and wind speed.

\section{Conclusions}

This paper presented an integrated solar heat pipe wall space heating system employing double glazed heat pipe evacuated tube solar collector and forced convective heat transfer condenser. A numerical model based on the energy balance mechanism was developed to simulate the performance of the solar system, which is able to predict some performance characteristics of the system, such as outlet air temperature, heat pipe temperature, absorber temperature, efficiency, and useful absorbed heat. Furthermore, the system performance was evaluated based on exergy

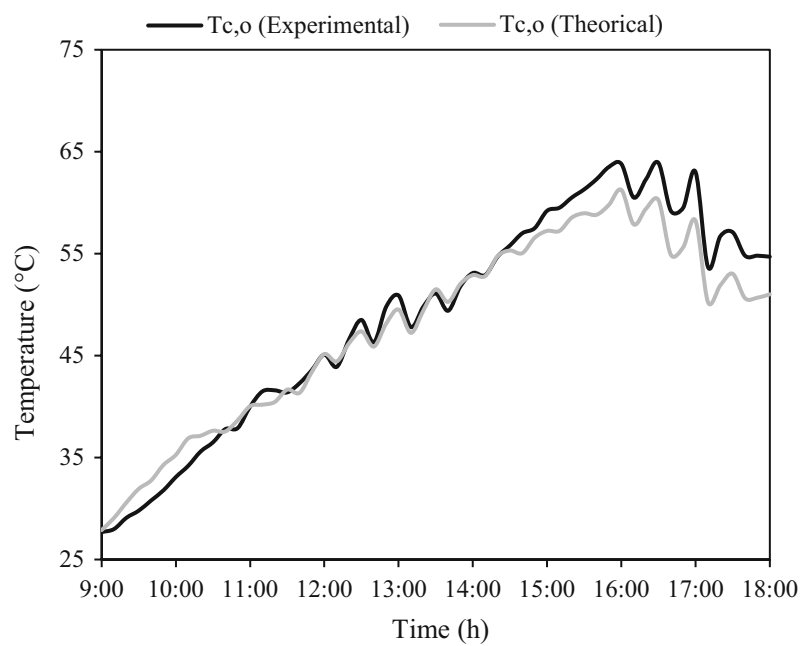

Figure 12. Evaluation of model with experimental results.

Table 3. Specifications of heat pipe solar collector.

\begin{tabular}{lc}
\hline Model & JDL-PM15-58/1.8 \\
\hline Absorber area $\left(\mathrm{m}^{2}\right)$ & 2.06 \\
Tube outer diameter $(\mathrm{mm})$ & 58 \\
Tube length $(\mathrm{mm})$ & 1800 \\
Number of tubes & 15 \\
Weight $(\mathrm{kg})$ & 74 \\
Volume $\left(\mathrm{m}^{3}\right)$ & 0.24 \\
\hline
\end{tabular}

efficiency. Finally, the capability of the proposed system to meet the heating demand of a building was investigated. The results were compared by experimental results to confirm the precision of the developed model.

The results indicated that the rate of increasing in temperature of air becomes negligible after 30 heat pipes, so applying a solar collector with more than 30 heat pipes is not efficient. The trend of the thermal efficiency is descending with increasing number of heat pipes. Parametric studies showed that several parameters had the most effect on the performance of the solar system such as thickness of the glass (1.43\%), transparency of the cover $(17 \%)$, conductivity of the insulating material $(2 \%)$ and absorber material $(1 \%)$. The proposed system with a 20 heat pipe collector shows the maximum energy and exergy efficiency of $55.8 \%$ and $7.2 \%$ which can afford warm air up to $30^{\circ} \mathrm{C}$ for the zone in a cold day of winter in January. It was also concluded that a proper way to increase the thermal covered area of the building by the solar air heating system is to apply parallel collectors, which increases the overall collector area and the overall delivered air mass flow rate while keeps the heat pipes less than 30 per collector, simultaneously. 


\section{Nomenclature}

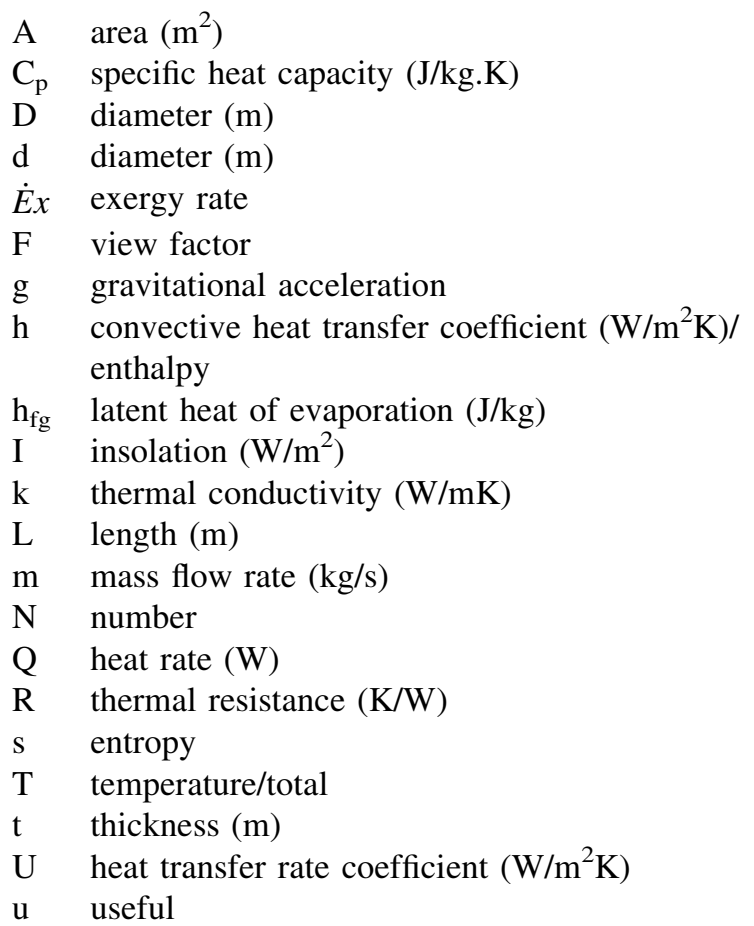

\section{Greek symbols}

absorptivity

thickness (m)

emissivity

dynamic viscosity (Pa.s)

thermal conductivity $\left(\mathrm{W} / \mathrm{m}^{2}\right)$

density $\left(\mathrm{kg} / \mathrm{m}^{3}\right)$

Stefan Boltzman constant

transmittance

efficiency

Indices

$\begin{array}{ll}\text { ab } & \text { absorber } \\ \text { amb } & \text { ambient } \\ \text { c } & \text { coating material on absorber } \\ \text { e } & \text { evaporator } \\ \text { dest } & \text { destroyed } \\ \mathrm{g} & \text { glazing cover } \\ \mathrm{hp} & \text { heat pipe } \\ \mathrm{i} & \text { inner/inlet } \\ \mathrm{k} & \text { location } \\ \mathrm{l} & \text { liquid } \\ \mathrm{o} & \text { outer/outlet } \\ \mathrm{p} & \text { pipe } \\ \mathrm{V} & \text { vapor } \\ \mathrm{Sc} & \text { solar collector } \\ \mathrm{Sr} & \text { solar radiation } \\ \mathrm{w} & \text { wick } \\ \mathrm{u} & \text { useful } \\ 0 & \text { dead state }\end{array}$

\section{References}

[1] Dunn P D and Reay D A 1982 Heat pipe, 3rd edition, New York: Pergamon Press

[2] Faghri A 1995 Heat pipe science and technology. London: Taylor \& Francis

[3] Corliss J M 1979 Evaluation of heat pipe application for passive solar systems. DOE Report Department of Energy, Washington DC

[4] Rice W J 1984 Performance of passive and hybrid solar heating systems. Int. J. Ambient Energy 5(4): 171-186

[5] Albanese M V, Robinson B S, Brehob E G and Sharp M K 2012 Simulated and experimental performance of a heat pipe assisted solar wall. Sol. Energy 86(5): 1552-1562

[6] Robinson B S, Chmielewski N E, Knox-Kelecy A, Brehob E G and Sharp M K 2013 Heating season performance of a fullscale heat pipe assisted solar wall. Sol. Energy 87: 76-83

[7] Du B, Hu E and Kolhe M 2013 An experimental platform for heat pipe solar collector testing. Renew. Sustain. Energy Rev. 17: $119-125$

[8] Varga S, Oliveira A C and Afonso C F 2002 Characterization of thermal diode panels for use in the cooling season in buildings. Energy Build. 34(3): 227-235

[9] Chan H Y, Riffat S B and Zhu J 2010 Review of passive solar heating and cooling technologies. Renew. Sustain. Energy Rev. 14(2): 781-789

[10] Rosen M A and Dincer I 2003 Exergy methods for assessing and comparing thermal storage systems. Int. J. Energy Res. 27(4): 415-430

[11] Szargut J, Morris D R and Stewart F R 1998 Exergy analysis of thermal, chemical and metallurgical processes. USA: Edwards Brothers Inc

[12] Akpinar E K and Koçyiğit F 2010 Energy and exergy analysis of a new flat-plate solar air heater having different obstacles on absorber plates. Appl. Energy 87(11): 3438-3450

[13] Bouadila S, Lazaar M, Skouri S, Kooli S and Farhat A 2014 Energy and exergy analysis of a new solar air heater with latent storage energy. Int. J. Hydrogen Energy 39(27): 15266-15274

[14] Gunerhan H and Hepbasli A 2007 Exergetic modeling and performance evaluation of solar water heating systems for building applications. Energy Build. 39(5): 509-516

[15] Bayrak F, Oztop H F and Hepbasli A 2013 Energy and exergy analyses of porous baffles inserted solar air heaters for building applications. Energy Build. 57: 338-345

[16] Wang Z, Duan Z, Zhao X and Chen M 2012 Dynamic performance of a facade-based solar loop heat pipe water heating system. J. Sol. Energy 86(5): 1632-1647

[17] Riffat S B, Zhao X and Doherty P S 2005 Developing a theoretical model to investigate thermal performance of a thin membrane heat-pipe solar collector. Appl. Therm. Eng. 25 (5-6): 899-915

[18] Lienhard J H IV and Lienhard J H V 2008 DOE fundamentals handbook: thermodynamics, heat transfer, and fluid flow. Washington, DC: US Department of Energy

[19] Incropera F and DeWitt D 2002 Introduction to heat transfer, 5th edition, New York: Wiley

[20] Azad E 2008 Theoretical and experimental investigation of heat pipe solar collector. Exp. Therm. Fluid Sci. 32(8): 1666-1672 
[21] Bienert B 1973 Heat pipes for solar collectors. In: Proceedings of the 1st international heat pipe conference, Stuttgart, Germany

[22] Hartley A 2006 Fuel poverty. Birmingham: West Midlands Public Health Observatory

[23] Tabatabaee M H 2008 Construction installation calculation. Tehran: Kelid Amoozesh pub

[24] Singh N, Kaushik S C and Misra R D 2000 Exergetic analysis of a solar thermal power system. Renew. Energy 19(1-2): 135-143
[25] Petela R 2003 Exergy of undiluted thermal radiation. Sol. Energy 74(6): 469-488

[26] Peters Ca 2001 Statistics for analysis of experimental data. Champaign, IL: Environmental Engineering Processes Laboratory Manual, AEESP

[27] Trnsys 16.00.0037, 2005 Weather data reading and processing 